\title{
Network Advertising Design Strategy in the Background of Central Plains Economic Zone
}

\author{
Zhenglei Dong \\ Huanghe Science and Technology College \\ Zhengzhou, China
}

\begin{abstract}
The construction of the Central Plains Economic Zone and the rapid development of the Internet have brought an unprecedented opportunity for the advertising industry. With the development of communication technology, the traditional advertising design strategy has lost its past vitality, which makes us redefine and think about the operation and development of the whole advertising design strategy.
\end{abstract}

Keywords—network advertising; audience; design strategy

\section{INTRODUCTION}

With the popularization and continuous update of the network and technology, people's cognitive ability and appreciation ability are greatly improved. The average network advertising design can no longer meet the needs of modern people, which requires the strong support of highquality advertising. A good advertising can make people remember, but it also requires designers to consider many aspects and understand the market and experience life, know the current consumer trends, understand the use of advertising design strategies and expression techniques, and thus formulate corresponding advertising strategies.

\section{VISUAL STRATEGY}

The information dissemination of advertising is carried out in the form of visual sense and auditory sense, and the information transmission of the network advertising is mainly based on the visual image. According to the research analysis, more than $85 \%$ of the information people acquire is through the visual sense from the outside world. If use network advertising to convey a certain kind of information, we shall use text, image, color, composition and other visual elements, and reasonable and effective methods. That is to say, only by using the scientific visual language strategy can we make a success. Visual strategies mainly include text, graphics, color, layout, and so on.

\section{A. Text Design}

In the visual communication design of the network advertising, the text can play the function of explanation, and the shape of character has visual expression ability. Text design is an important part in design. In the design process of network advertising, we should grasp the following points in terms of text design. First, the text shall be readable. Text is the basic tool of information transmission in the network advertising, so text shall convey all kinds of information contents and intentions to audiences accurately and clearly and meet the requirements of modern advertising information about speed and efficiency. Therefore, we shall avoid using complicated and messy text, but use concise and understandable text; otherwise, it will cause obstacles in communication. Second, the text design shall be personalized. The texts of different characteristics have different personalities and visual effects in different images. In the same web page, a wide variety of ads are full of pages. Those ads with personalized text design have better visual effect than general text ad in publicity. According to the management concept, cultural background and industrial characteristics of advertising information and other factors, to create different personalized character styles can be a good way to show and explain the personality of related products and services. Third, use uniform modeling. The text design of network advertising shall be determined according to the overall design style of the advertising. Advertising font is to convey the product information through its own modeling features, so it shall have a visual sense of the overall aesthetics, and strive to achieve the perfect effect and beautiful image, to attract the audience's attention and improve the effectiveness of communication.

\section{B. Graphic Design}

Graphics is the main component of network advertising, which can vividly display the theme and the originality of advertising. According to the research, the text information on the expression and understanding is easy to appear error and lack fidelity. In addition, the differences of text language are easy to cause the communication barrier. And its information content is far less than that of the advertising graphics. The information capacity of the advertising graphics is 900 times of the text information. In short, for information dissemination activities, the form of advertising graphics has a lot of advantages. Japanese Linguist Tokieda Motoki said: "The impression obtained through language is abstract, perishable, and may only have general value, and it takes time to master it. And the impression obtained through the image is specific; we can see certain example and remember it at the moment". It can be seen that compared with language expression, the effect of image information is often better than thousands and thousands of words. The use of visual language of graphics to disseminate information has the characteristics of visualization, direct viewing and 
materialization. Visual language is a universal language. In modern network advertising design, it is an important topic in today's visual communication design to use simple visual forms containing rich information content to disseminate information quickly and accurately. It is also a requirement of modern people for consumption culture and fast-paced modern life for advertising design. Especially in the information explosion era, people only have a tiny sip of information. Overly complex graphics often lack a strong visual impact, so graphic design should be simple, lucid, and understandable, easy to recognize, understand and memory for audiences.

\section{Color Design}

Color in the advertising performance has a quick appeal to feelings. It is closely related to the physiological and psychological reactions of the audience. The first impression of the audience is obtained through the color. Good color design can give a strong visual impact and artistic appeal, can lead people to understand and appreciate the image and content in the aesthetic sense. In the use of color in network advertising, it shall show the theme and originality of advertising, and fully demonstrated the charm of color.

First of all, analyze and review the advertising theme and choose a reasonable technique of expression. Each color has its own emotional effect and symbol, so designers can choose colors and appropriate technique of expressions according to the theme. Designers can use the expressive force and emotional effect of color itself to combine the content and form, and use colors to reflect the theme and style of the advertising. Secondly, it shall be distinct. With a numerous of advertising gathered on the Internet, only the advertising with distinct color has its unique style and can show bright personality characteristic, leaving visitors a deep impression. Advertising color should comply with color characteristics of the products colors and has the originality, so the network advertising can be attractive and has a better propaganda effect. Thirdly, it shall be unified with visitors' aesthetic temperament and interest. There are a lot of differences in people's life experience, age, cultural background, customs, physiological reaction, nationality, religious beliefs, etc. And our aesthetic perspective and aesthetic ability are also various. Different visitors have different association and understanding of same color. We are also different in the degree of preference on color. So designers should try to match colors in line with the aesthetic tendency of visitors in network advertising design, meanwhile care about fashion colors of the society in certain period. It is because that the fashion colors have a very strong attraction and impact force, and it can attract more visitors, and thus the network advertising will be able to produce better publicity effect.

\section{Layout and Arrangement}

The visual communication design of network advertising should be influenced by composite factors, such as the objective conditions and reception psychologies of the audience. Therefore, designers should pay more attention to the scientific, practical and artistic quality in the layout of network advertising. Network advertising is a visual and auditory language. It is particular about page layout and arrangement, which is extremely prominent in the full screen type of network advertising. Designer should make full use of contrast and harmony, rhythm and other techniques to create a harmonious relationship among space, text and graphics, so as to produce a harmonious beauty, such as the advertisements of Beijing Fuxingbao Kitchen Ware Co., Ltd. The page layout of network advertising is to increase of the value of attention and attraction to audiences, so as to leave them a good impression and deep memory. In a short, designers shall follow the following principles in page layout and arrangement of network advertising. First, strive to be simple, clear and well arranged in order to leave a moment visual impact on audiences and attract audiences' attention. Second, forms and languages shall be consistent with the content of advertising and express the rich meaning of the products. Third, emphasize the appeal points on the page. In the layout design of network advertising, highlight size, position, virtual-real comparison and forms in order to attract audience attention immediately and arouse their interests and desires. Fourth, be particular about white space handling in the layout design. The white space handling has an important role in improving the visual effect of the layout. It not only makes layout smooth, lucid, and orderly, but also creates a strong concentration effect on the vision, which is in favor of highlighting the appeal of the advertising.

\section{CReative StRATEgy}

Advertising creative strategy refers to new, original and creative ideas for the purpose of the performance of the theme of the advertising. Network advertising creative strategy can be understood as overall design idea of the advertising staff on certain theme to use relevant multimedia technology and network technology, to give full play to the role of figure, text and color, to mobilize the audience's emotions, and to achieve the role of propaganda products. Network advertising creative strategy is the key to influence the effect of advertising.

\section{A. Relevance Strategies}

Network advertising relevancy creative strategy refers that the originality of advertising has a natural inner link with products or services, advertising target object, and the enterprise's competitors. When people see the advertising, they can automatically associate to the relevant enterprises, products or services, specific consumer groups, etc. It can make audiences produce a psychological reaction in favor of advertiser. To find out the relevance of the product and the consumer, in essence, is to find the creative point of advertising. If the object of advertising is white-collar consumer, designers shall research the consumption characteristics of the consumer groups to design advertising that gets them interested and attracts them to click on the ads, and then generate a desire to buy.

\section{B. Interactive Strategy}

Interactivity is a big characteristic of network advertising. In the network advertising, designers can use Flash, Java and 
other technical means to enable the target audience to participate in the interactive advertising itself. It is in favor of consumers to reduce the harassment of useless ads, but only to access to the contents on their interest in depth. And their demand and willingness are fully respected. Advertisers can change network advertising based on the interests and hobbies of consumers, and design advertising suitable for the audience tastes. The interaction design and the effect on web page directly affect the information transmission of the network advertising, so it is conducive to improve the click rate of advertising to make full use of the interactive features of the network advertising in creative network advertising.

\section{Aesthetic Strategies}

Network advertising is the carrier of the dissemination of product information. It expresses a certain content theme and ideas, and communicates and interacts with the public in the virtual space of the Internet in order to meet the needs of Internet users. The advertising design in the media web page, in particular emphasis on the integrity of the various links, so that visitors can understand the information content and main ideas on media website fast, accurately and comprehensively. It leaves visitors an impression of tight internal relation and a beauty of external harmony and integrity. The network advertising design shall emphasize the common characters of each part of the advertising page; at same time reflect the personality characteristics of the part in order to obtain an overall beauty of the design form of advertising page. Designers shall start from color, style, layout design, with careful organization and accurate positioning to get the order of the advertising page, but also pay attention to create a harmonious relationship between pictures and pictures, pictures and text, text and text, and create a harmonious beauty, so as to create a perfect advertising design mood and give people a visual enjoyment.

\section{Affinity Strategy}

Affinitive network advertising can give consumers a kind, friendly psychological feeling with a pleasing way, and create a just, sincere and credible emotional atmosphere. This emotional atmosphere invisibly conveys the information of goods and services. Modern network advertising creativity is very much focused on the use of emotion. Especially that network advertising with a strong emotional theme pays more attention to the rendering of emotional color on the creative performance. Advertising picture makes consumers immersed in pleasure of advertising image, so that consumers consciously accept the persuasion of advertising.

\section{E. Brand Image Strategy}

With the improvement of living standards, China's consumers have begun to pay attention to choose the brand. The pursuit of brand is gradually becoming a universal consumer psychology. Brand consumption becomes a fashion. In addition, due to the identical trend of similar products, the differences of similar products are shrinking. Consumers often choose to buy products according to the degree of the likes and dislikes of brands. Therefore, the application of brand image strategy in the network advertising is more and more valued by the advertisers. Brand image is the association of people on advertising commodity quality and individual emotional reaction, including external association and internal association. It is related to visibility, reputation and popularity. In the modern consumer behavior, with the change and update of people's ideas, most people always consciously or unconsciously adapt to the changes of the times, to show that they are synchronized with the times and in line with the trend of the times, and thus in the consumer field, there is a trend of mutual imitation and chase fashion. Nowadays, merchants often invites famous persons to advocacy their network advertising as their spokesmen, for it can arouse the audience's consumer passion, and arouse the audience's desire to consume the brand products.

\section{F. Shock Strategy}

The originality of the network advertisement should have the characteristic of shock, leaving people a strong and unforgettable psychological impact. Creative performance should have a unique personality in order to give people a new feeling. And it can give the advertising work a special form of beauty and produce a strong appeal and shock, so that the advertising can arouse the attention and interest of the audiences. Take the advertisement of "Bit Copa" beer as example. The lively and imaginative advertisement picture has a great impact and can make people remember it forever. The network advertisement uses the art of human body as its unique technique of expression. The combination of classical creativity and body art is shocking, unexpected and appropriate. The harmonies combination enhances the beauty of each other. Therefore, it can be regarded as the best in the field of network advertising.

\section{CONCLUSION}

Twenty-first Century is a digital and personalized consumer era, and a strategy-subduing era. After joining WTO and the increasingly maturity of the buyer's market, China's advertising industry is facing increasingly fierce challenges of competition in the scope, ways, methods, and means. Competitive strategy has become the core issue of the advertisers. To develop China's network advertising, we shall understand the current consumer culture in China and establish a correct strategy for advertising design. We must strengthen the network advertising strategy management, and take effective countermeasures, to form our own core ideas, so that the network advertising can develop in a rapid, sustainable and healthy way.

\section{REFERENCES}

[1] Jane Jacobs (Japan). Modern Social Theory - Present and Future of Information and Consumption Society. Beijing: International Culture Press, 1998 edition.

[2] Edited by Mark Post. Jean Baudrillard: Selected Writings, Stanford University Press, 2001 edition.

[3] Chao Naipeng \& Du Junfei. The Principle of Network Advertising and Practice. Fujian: Fujian People's Press, 2005 edition. 
[4] Liu Youlin, editor in chief. Network Advertising Practice. Beijing: China Radio and Television Press, 2003 edition. 